\title{
RELIGIOSIDADE, CULTURA MATERIAL E ARTE PARA O ESTUDO DOS EX-VOTOS PORTUGUESES DA ÉPOCA MODERNA AO PRESENTE
}

\author{
Isabel Maria Mendes Ribeiro Drumond Braga ${ }^{1}$ \\ O artífice dos milagres é Deus, o instrumento deles é a fé
}

(BLUTEAU, 5, 1716, p. 482)

Resumo: O texto tem como principal objetivo chamar a atenção para o potencial dos ex-votos enquanto fontes para o estudo da cultura material e da religiosidade. Por outro lado, pretende-se igualmente alertar para as diferenças entre os ex-votos do passado e os da atualidade, tendo em perspetiva novos entendimentos acerca do conceito de milagre, distintos da conceptualização original.

Palavras-chave: Ex-votos. Milagres. Religiosidade. Cultura material. Portugal.

\section{RELIGIOSITY, MATERIAL CULTURE AND ART FOR THE STUDY OF PORTUGUESE EX-VOTES FROM THE MODERN TIME TO THE PRESENT}

Abstract: The main objective of the text is to be awere to the potential of the ex-votes as sources for the study of material culture and religiosity. On the other hand, it is also intended to understaind the differences between past and present ex-votes, in view of new understandings of the concept of miracles, distinct from the original conceptualization.

Keywords: Ex-votos. Miracles. Religiosity. Material culture. Portugal.

\section{RELIGIOSITÉ, CULTURE MATÉRIELLE ET ART POUR L'ÉTUDE DES EX- VOTES PORTUGAIS DE L'ÈRE MODERNE À AUJOURD'HUI}

Resumé: Le principal objectif de ce texte est regarder le potentiel des ex-votes comme sources pour l'étude de la culture matérielle et de la religiosité. D'autre part, le texto est également destiné à penser les différences entre les ex-votes du passé et du présent, en vue de nouvelles interprétations du concept de miracle, distinctes de la conceptualisation originale.

Mots-clé: Ex-votos. Miracles. Religiosité. Culture matérielle. Portugal.

\section{RELIGIOSIDAD, CULTURA MATERIAL Y ARTE PARA EL ESTUDIO DE EX VOTOS PORTUGUÉS DEL TIEMPO MODERNO AL PRESENTE}

Resumen: El objetivo principal del texto es llamar la atención sobre el potencial de los ex-votos como fuentes para el estudio de la cultura material y de la religiosidad. Por otro lado, también se pretende llamar la atención sobre las diferencias entre ex-votos pasados y presentes, en vista de nuevas interpretaciones del concepto de milagro, distintos de la conceptualización original.

Palabras-clave: Ex-votos, milagros, religiosidade, cultura material, Portugal.

Manifestações artísticas, culturais e marcas de religiosidade, os ex-votos constituem provas materiais dos gestos de gratidão do Homem face ao divino, após um momento de aflição. Efetivamente, trata-se de uma prática bastante anterior à Época Moderna, documentada, pelo menos desde a Antiguidade clássica e associada aos

1 Doutora em História Económica e Social pela Faculdade de Ciências Sociais e Humanas da Universidade Nova de Lisboa. Docente da Faculdade de Letras da Universidade de Lisboa.

Revista Escritas do Tempo - v. 1, n. 3, nov/2019-fev/2020 - p. 79-96 
cristãos a partir do século IV. Importa, pois, perceber se há diferenças entre os motivos que levavam à entrega de um ex-voto num santuário outrora e na atualidade. Por outro lado, cabe salientar o potencial destas fontes para o estudo da cultura material do passado e do presente.

\section{A historiografia dos ex-votos}

Nos últimos anos a historiografia começou a prestar atenção ao potencial das fontes iconográficas e, no caso que nos ocupa, dos ex-votos em particular, como uma fonte relevante para o estudo da cultura material. Efetivamente, iluminuras relativas aos meses do ano, miniaturas em códices, últimas ceias, naturezas mortas, alegorias e ilustrações científicas, pintura dita de género, apresentando lojas, mercados, tabernas e interiores domésticos, recriam ambientes, gestos e objetos que são familiares aos contemporâneos do momento em que foram realizadas. Ao situarem acontecimentos e espaços conhecidos, os artistas procuram a proximidade e a identificação de quem contempla a peça de arte. Não se trata de apresentar um episódio notório a um público que domina a informação, mas de fazê-lo implicar-se nesse acontecimento, estabelecendo uma relação mais profunda, de modo a provocar uma reação no espetador.

No entanto, em Portugal, poucos têm sido os trabalhos produzidos sobre exvotos de per si. Isto é, na maior parte dos casos estamos perante catálogos de peças relativas a um santo, como por exemplo Santo António (REMA, 2003), a um conjunto com unidade temática, caso das coleções particulares (Milagre, 1997), das coleções de um determinado santuário, tais como o do Senhor de Matosinhos (ARAÚJO, 1979) ou o de Nossa Senhora de Balsamão (RODRIGUES, NAITO, s.d.); a uma determinada geografia, por exemplo, os que se referem a episódios ocorridos no Brasil durante o período moderno (Estórias, 1998), ou os que têm como palco a Baía (Estórias, 1999); a um santuário ou diocese, citem-se os de Portalegre-Castelo Branco (Imagens, 2015), ou de estudos sobre religiosidade, nos quais se encontram algumas informações sobre as oferendas dos peregrinos, tais são os casos, de entre outros, dos que se referem aos santuários de Guadalupe (Espanha) (MENDES, 1994), de Nossa Senhora das Virtudes (BEIRANTE, 2004), de São Gonçalo de Lagos (GUIMARÃES, 2004) ou de Nossa Senhora da Oliveira (FERNANDES, 2006). Encontram-se, contudo, algumas exceções. Veja-se o trabalho de Maria Ludovina Grilo sobre os ex-votos da ermida de Nossa 
Senhora do Carmo, em Azaruja (GRILO, 1997), dedicado às potencialidades destas fontes ${ }^{2}$.

Importa, pois, continuar a proceder ao levantamento, inventariação e salvaguarda deste património, para que o investigador possa estudá-lo sob diversos prismas, tanto mais que se trata de um conjunto de fontes que oferece um potencial muito variado, quer sob a ótica da história da arte quer sob as perspetivas da religiosidade e da cultura material. A abordagem que se pretende realizar neste texto parte da análise de ex-votos, portanto fontes iconográficas. Contudo, não se foca numa abordagem artística, antes tem como objetivo chamar a atenção para a potencialidade destas fontes para a cultura material e, tanto quanto possível, articular essa vertente com as informações que se podem encontrar nos chamados registos de milagres. Por outro lado, pretende-se perceber se há diferenças entre os ex-votos do passado e da atualidade e, em caso positivo, quais são as mudanças verificadas.

\section{Milagres e peregrinações}

Comecemos por esclarecer o significado do termo milagre, tanto mais que os autores que transmitiram e fixaram relatos miraculosos durante a Época Medieval nunca o fizeram (VAUCHEZ, 1999, p. 40). Para Rafael Bluteau, o milagre é obra da omnipotência divina, sobrenatural ou superior às forças dos agentes naturais, ou obra que pelo poder divino realizam os santos para benefício da fé e glória de Deus. O lexicógrafo considerou que os milagres foram particularmente úteis no início da Cristandade, para converter os infiéis, e acrescentou que eram obra divina superior a toda a faculdade criada e contra o curso normal dos acontecimentos. Indicou ainda exemplos de milagres e esclareceu: "não aprovo a pia credulidade de alguns, que de qualquer sucesso extraordinário fazem milagre. Não devemos ter por milagre senão o que excede todo o poder natural da criatura. O que é maravilha nem sempre é milagre" (BLUTEAU, 5, 1716, p. 482).

Se os milagres medievais ocorreram frequentemente junto dos santuários, perto das relíquias dos santos, uma maior distância tornava-os mais extraordinários. Contudo, o processo miraculoso compreende diversos momentos. Segundo Pierre-André Sigal, tudo começa com a invocação, isto é, quando o fiel entra em contacto com o santo para

\footnotetext{
${ }^{2}$ Um elenco da bibliografia portuguesa sobre ex-votos pode ser consultado em ARAÚJO, 1979 e em SOALHEIRO, 2000. Além dos autores portugueses, outros autores estrangeiros referiram o potencial destas fontes para o estudo da cultura material, tais foram, por exemplo, OLES, 2014 e ABREU, 2015.
} 
pedir a sua intermediação e assim obter uma graça, resolvendo um problema; segue-se o voto, por vezes condicional, evidenciando confiança e desconfiança no santo, acompanhado pela promessa, frequentemente uma peregrinação - as condições em que estas são realizadas têm frequentemente características penitenciais - e a entrega de uma oferenda. Após a peregrinação e a eventual oferta de um ex-voto, era comum o fiel rezar, ouvir missa, confessar-se e relatar o motivo da visita ao santuário (SIGAL, 1985, pp. 81-86). Finalmente, quer antes quer depois do Concílio de Trento, procedia-se ao controlo do milagre, com base em testemunhos oculares fidedignos e em interrogatórios.

Vejamos dois exemplos, um do século XV e outro da centúria de seiscentos, nos quais se identificaram os diferentes passos do processo miraculoso, a partir de dois depoimentos inseridos em livros de milagres ${ }^{3}$ :

Da moça, sã por Santa Maria, a que tirou a cabeça do dedo polegar [aflição] Em o ano do Senhor de 1497, no termo da cidade de Évora, em um monte, morava um lavrador que tinha uma filha de 13 anos, à qual nasceu uma apostemação em um braço, tão grande que lhe apodreceu o braço todo e determinado pelos físicos que lhe cortassem o braço, dizendo que não sabiam para ser sã outro remédio. [invocação] $\mathrm{E}$ em isto a moça houve medo e pediu que esperassem aquela noite e se queria encomendar à Virgem Maria das Virtudes. E foi feito assim que, encomendando-se a moça à dita Senhora das Virtudes, pareceu-lhe que, em dormindo, veio a ela uma muito excelente e formosa Senhora que lhe descobria e desatava o braço doente e, assim como lhe ia com a mão palpando o braço, assim o sarava até que chegou ao dedo polegar da mão direita. O qual apertando-lho muito a dita Senhora que lhe descobria e desatava o braço doente e, assim como lhe ia com a mão palpando o braço, assim o sarava até que chegou ao dedo polegar da mão direita. O qual apertando-lhe muito a dita Senhora, a moça com a dor espertou e bradou dizendo: a Senhora das Virtudes me deu sã. E estendido o braço foi achado todo são e a ponta do dedo polegar com a unha arrancada e desapegado da mão e posto aí junto na cabeceira da cama, ficando todo soldado como que nunca houvera mal algum. [ex-voto] $\mathrm{O}$ qual dedo o pai da moça encastoou em prata e o trouxe com a moça em romaria a Santa Maria das Virtudes [peregrinação] e aí o leixou na sacristia, por memória e aí está. [controlo] Testemunhas disto: muitos, scilicet, Frei Rodrigo de Soure, sacristão e o guardião e muitos outros, no dia de Santa Maria de setembro, que o viram e ouviram (BEIRANTE, 2004, p. 61).

Na festa de Nossa Senhora de setembro de 1602 veio a esta santa casa de Nossa Senhora de Guadalupe um devoto português que se dizia Manuel Rodrigues, natural da cidade de Elvas em Portugal, em cumprimento de um voto. [controlo] E sendo examinado da causa com juramento em forma, disse que estando a cidade de Elvas, muito afligida de pestilência no ano de 1599, ficou ferido com três landres, e ainda que os médicos o tenham assistido com cuidado, a sua enfermidade foi-se sempre agravando, tendo recebido os sacramentos e a

\footnotetext{
${ }^{3}$ Procedeu-se à atualização da grafia e, no segundo caso, à tradução do castelhano.
} 
extrema unção, despedindo-se os médicos que o deixaram nas mãos de Deus. [aflição] Veio a morrer e como tal o amortalharam, tirando-o da cama e pondo-o no chão sobre um leito para o levar a enterrar, como se costuma fazer. [invocação] Nesse momento, a sua mulher muito aflita de ver tanta dor diante dos olhos pondo-se de joelhos no chão e olhando para o céu, disse com grande ânsia no seu coração: 'Virgem de Guadalupe ressuscitai o meu marido que eu vos prometo de o levar à Vossa Santa Casa e [voto] oferecer a mortalha e fazer dizer uma missa Vossa Reverência". Neste ponto foi Nosso Senhor servido por méritos de sua santa Mãe de ressuscitar o defunto que, levantando-se ergueu as mãos, descobriu o rosto e dizendo sua mulher 'o que é isto?' Ele, como homem muito cansado, respondeu: 'estou muito cansado'. Voltou logo para a cama, trataram-no e ficou bom e são e convalesceu rapidamente sem sentir mais as landres, nem outro mal algum. Todas estas coisas contava este devoto da Virgem com muitas lágrimas e devoção e estes sentimentos particulares de homem que se tinha visto naquele artigo, e em tudo parecia homem de bem e de crédito e vinha com ele outro homem honrado daquela cidade e jurou ter ouvido contar o caso na terra (BRAGA, 1993, p. 96).

Trata-se de um género literário da autoria de homens da Igreja, baseado nos relatos dos populares, em concreto dos miraculados e das testemunhas oculares dos milagres, povoado, muitas vezes, pela presença do maravilhoso. A análise deste tipo de fontes permite perceber quais os motivos que levavam os fiéis a visitar os santuários para dar cumprimento aos votos. Foram os problemas de saúde os que mais pessoas fizeram movimentar. O frágil domínio sobre o corpo, o estádio de desenvolvimento da medicina, a alimentação escassa e desequilibrada e a ignorância acerca de determinados preceitos fizeram com que muitos, perante um problema de saúde, um acidente ou um parto, pedissem a intercessão dos santos e, obtida a graça, fossem em peregrinação. Nas fontes, são referidos como pessoas feridas, que haviam padecido de "calenturas", ficado "tolhidos", conhecido o flagelo da peste, ou perdido o juízo. O cativeiro em terras do Islão, as tempestades e os naufrágios, as questões relacionadas com a justiça, não raro a possibilidade de ser condenado injustamente ou com uma pena pesada, e um leque de outros motivos que vão desde os problemas decorrentes da guerra, os perigos das viagens terrestres, as pragas sobre as culturas, as quedas de telhados, as enxurradas, etc. foram igualmente motivantes de peregrinações para cumprir promessas.

Não obstante a profusão de milagres escritos desde a Idade Média, que chegaram até ao presente, só a historiografia a partir da segunda metade do século XX lhes parece ter dado valor enquanto fontes históricas ${ }^{4}$. Assim se compreendem as reflexões de Benedicta Ward, relativas a estas fontes, as quais são igualmente verdadeiras para a Época Moderna:

\footnotetext{
${ }^{4}$ Para Portugal vejam-se os trabalhos de BEIRANTE, 2004 e OLIVEIRA, 2019.
} 
The records of miracles in the Middle Age are not merely bizarre sidelights to the religion of the period. They provide, rather, a way to approach the ordinary day-to-day life of men and women in all kinds of situations and in all ranks of society, and serious historiens must take them into consideration (WARD, 1987, p. 214).

Nos reinos católicos da Europa do período moderno, peregrinações e milagres continuaram, o que se pode verificar de forma cabal quer pelos registos de milagres quer pelos processos de canonização ${ }^{5}$, independentemente de se fazerem ouvir algumas críticas aos mesmos. Porém, nas regiões em que as confessionalizações protestantes imperaram, os milagres foram, compreensivelmente, atacados e desacreditados, mas não totalmente postos de lado. Se para diversos reformadores do século XVI, aqueles haviam terminado nos tempos bíblicos ${ }^{6}$, para alguns grupos de protestantes ingleses importava fazer face ao excessivo racionalismo e verificar a veracidade das ocorrências. Assim, desconfiava-se dos milagres uma vez que estes pressupunham a intermediação dos santos e, por vezes, o recurso às relíquias, ou seja, porque implicavam algumas das questões atacadas pelos reformadores. Porém, foi-se caminhando para a sua aceitação, em especial durante o século XVIII:

The age of miracles may have been declared over by some Protestant Reformers, including key figures of the late England Reformation period, but signs and wonders, events and objects wich were beyond naturalistic explanations, continued to cause widespread comment and interest in postReformation England, and Protestants strongly believed in the intervention of God in the world (SHAW, 2006, p. 30).

\section{Votos e ex-votos}

Obtida a graça e levada a efeito a peregrinação era comum deixar uma oferenda no santuário. Alguns dos miraculados fizeram acompanhar-se de ex-votos, isto é, na definição de Rafael Bluteau, "o que se pendura no altar de um santuário e em satisfação dos votos que se fez. Há votos de cera, de prata e em quadros” (BLUTEAU, 8, 1721, p. 582). Contudo, o lexicógrafo não utilizou a expressão latina ex-voto, optou por voto com este e com outro significado: "é uma promessa feita a Deus ou a algum santo. Deliberada e voluntariamente, com o coração ou com palavras, de cousa boa e mais boa (sic) que sua contrária, como rezar, jejuar, etc.” (BLUTEAU, 8, 1721, p. 580).

\footnotetext{
${ }^{5} \mathrm{O}$ peso da doença relativamente aos milagres que justificaram os processos de canonização dos santos do século XVII, pode ser visto em BURKARDT, 2004.

${ }^{6}$ Esta situação não era desconhecida em Portugal. Rafael Bluteau, a ela se referiu na entrada milagre ao escrever: "nesta cegueira vivem os calvinistas e outros hereges que obstinadamente defendem que depois da ressurreição de Cristo não houve mais milagres no mundo" (BLUTEAU, 5, 1716, p. 482).
} 
O voto, considerado por Burkardt como um contrato de troca entre o devoto e o santo, que implica um esforço de reverência cuja modalidade fica à escolha do crente (BURKARDT, 2004, p. 410), nem sempre teve grande visibilidade devido à sua natureza privada e sem intermediação clerical. Porém, terá permitido a construção e a dotação de muitos santuários e capelas (CHRISTIAN JR., 1991, p. 48). O ex-voto, uma consequência do voto, implica investimento emocional (HOLMES, 2009, p. 160) e tem valor probatório, uma vez que deixa no santuário para os vindouros um testemunho do acontecido. Nas palavras de Catrien Notermans e Willy Jansen, "throu obtaining a more or less permanent place in the sacred space, the votive gift extends and reinforces the relationships between the devote and the saint; the drama expressed by the ex-voto also becames publicly displayed and reconized" (NOTERMANS, JANSEN, 2015).

O ex-voto pode ser definido em função das suas caraterísticas. Por exemplo, João Soalheiro propõe uma análise dividida em três núcleos: simbólicos (objetos anatómicos, zoomórficos ou velas), narrativos (objetos que contam um episódio concreto pela imagem, pelo texto ou por ambos) e de paramento (objetos que se destinam direta ou indiretamente ao culto) (SOALHEIRO, 2000, p. 236). Contudo, a tipologia proposta por Sigal (1985, p. 94-116) parece particularmente operacional. Isto é, objetos simbólicos (cera), representações figuradas (partes do corpo humano), objetos testemunhos do milagre (cordas de enforcados, ferros de cativos, mortalhas, ...) e oferendas compensatórias (escravos, joias, quantias monetárias, objetos litúrgicos, produtos agrícolas ou de pecuária, trabalho). Igualmente relevante é a classificação de Wiślicz, a saber: objetos quotidianos associados ao problema sentido pelo crente (cordas, ferros, etc.), objetos preparados especialmente para representar o drama vivido (pinturas, partes do corpo humano em cera, panos de mortalhas, ferros de cativeiro, etc.) e objetos não relacionados com a experiência (joias, roupas, cereais, quantias monetárias, etc.) (WIŚLICZ, 2010, pp. 177-179).

Os ex-votos traduzem gestos e criam memórias (SOALHEIRO, 2000, p. 236). Narram vivências pessoais ou coletivas - por vezes referem-se a toda uma comunidade que se salvou de um surto de peste ou de uma praga que não atacou as colheitas - e publicitam a proteção divina, o que lhes permite assumir um papel didático ao gosto de Trento e um caráter evangelizador, contribuindo igualmente para a fama de um santuário ou de uma pequena ermida.

Detenhamo-nos nos ex-votos sob a forma de quadros pictóricos, a maior parte dos quais com a inclusão de imagens e de texto. Tornaram-se comuns na Época 
Moderna e residuais na atualidade, sendo substituídos por gravuras e, sobretudo, por fotografias. Fazendo recurso dos mais variados materiais, tais como tela, madeira, cartão, papel, seda, etc., o quadro, retábulo ou painel narrativo, apresenta quase sempre os seguintes elementos: o santo que se invocou, por vezes circundado por nuvens, entendidas como manifestações do divino; o fiel ou alguém para quem este solicitou a graça, portanto, o autor do voto; e elementos que permitem contextualizar o problema, por exemplo, uma cama, uma embarcação no mar, um animal em perigo, etc. Comumente na parte inferior, encontra-se uma legenda mais ou menos elaborada com elementos que permitem perpetuar os nomes dos protagonistas e as situações vividas, a qual evidencia o caráter gratulatório. Reforçando a autoria popular, não raramente se encontram erros ortográficos no texto.

Produzidos com a finalidade de agradecer, os ex-votos importam ser vistos como objeto de estudo tendo em conta as condições sociais e culturais da produção e receção de imagens. Na maior parte dos casos, de autoria desconhecida, presumivelmente saídos das mãos de artistas modestos ou de simples curiosos, eventualmente por encomenda (ARAÚJO, 1979, p. 38; GRILO, 1997, p. 157; ABREU, 2005, p. 204) são peças maioritariamente ingénuas, cujo valor imagético é menos relevante do que o fim para o qual foram produzidas. Revelam a condição social dos ofertantes, nem todos dos grupos mais pobres, como frequentemente se afirma. Atendendo a que a análise dos livros de milagres tem revelado elevadas percentagens de graças relativas a problemas de saúde de adultos e crianças, incluindo abortos e partos, não é de estranhar que uma parte significativa dos ex-votos se refira a curas de enfermidades e ferimentos. Vejam-se alguns casos.

Figura 1: Ex-voto relativo a questões de saúde ${ }^{7}$

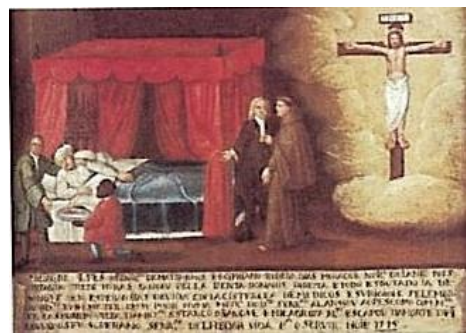

Fonte: Estórias, 1998.

\footnotetext{
7 Transcrição do texto do ex-voto: Milagre que fez o Senhor de Matosinhos [a] Cipriano Ribeiro Dias, morador no Rio de Janeiro, pois tendo botado treze horas sangue pela venta direita do nariz, e todo esgotado já de sangue, sem esperanças de vida, com assistência de médicos e cirurgiões, se lembrou o dito enfermo ter em seu poder uma medida do dito Senhor. A lançou ao pescoço com muita fé, e à segunda volta da medida estancou o sangue e milagrosamente escapou da morte. De que louva o seu soberano Senhor de lhe dar vida para o servir hoje. 1745.
} 
Figura 2: Ex-voto relativo a questões de saúde ${ }^{8}$

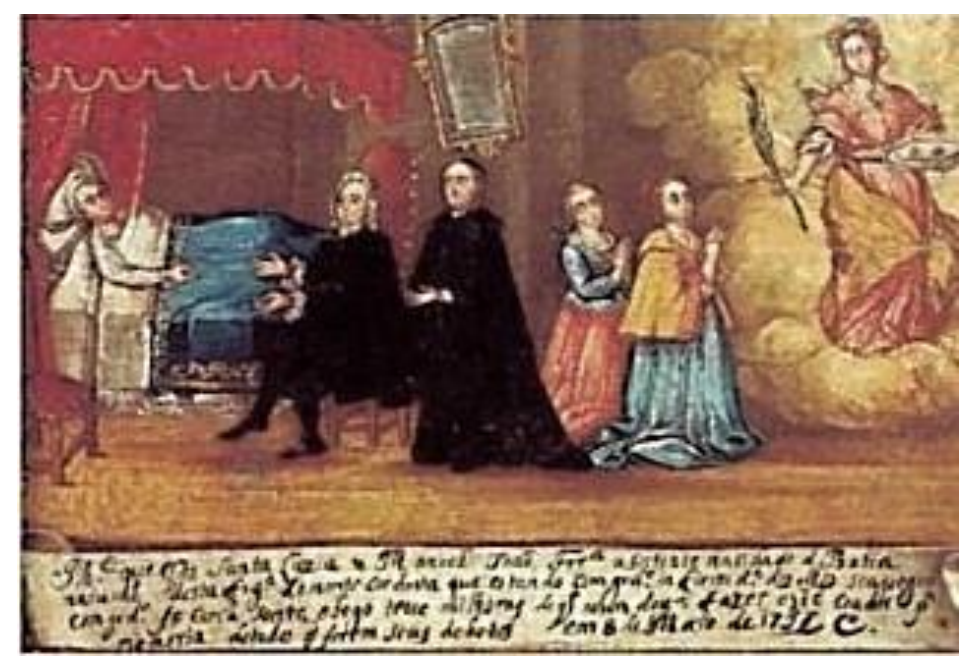

Fonte: Estórias, 1998.

Figura 3: Ex-voto relativo a questões de saúde ${ }^{9}$

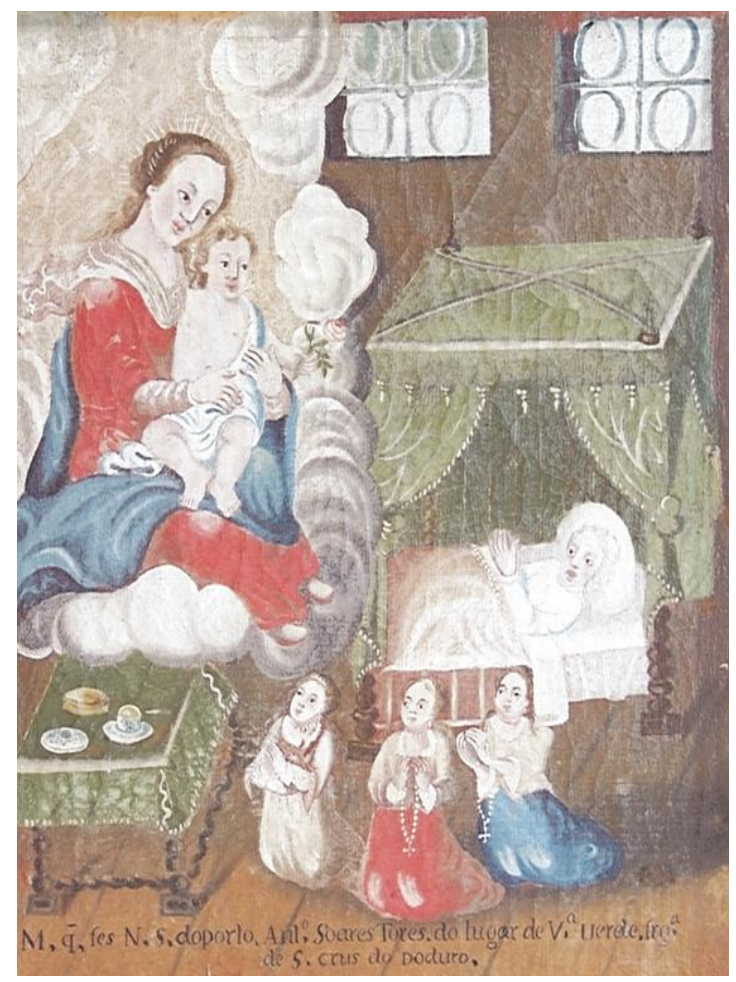

Fonte: ARAÚJO, 2006.

\footnotetext{
${ }^{8}$ Transcrição do texto do ex-voto: Milagre que fez Santa Luzia a Manuel João Ferreira, assistente na cidade da Baía, natural desta freguesia de Monte Córdova, que estando com grande enfermidade nos olhos, se apegou com grande fé com a Santa. E logo teve melhoras, de que mandou fazer este quadro, para memória de todos que forem seus devotos. Em 8 de maio de 1757.

${ }^{9}$ Transcrição do texto do ex-voto: Milagre que fez Nossa Senhora do Porto de Ave a António Soares Torres do ligar de Vila Verde, freguesia de Santa Cruz do Douro.
} 
Figura 4: Ex-voto relativo a questões de saúde ${ }^{10}$

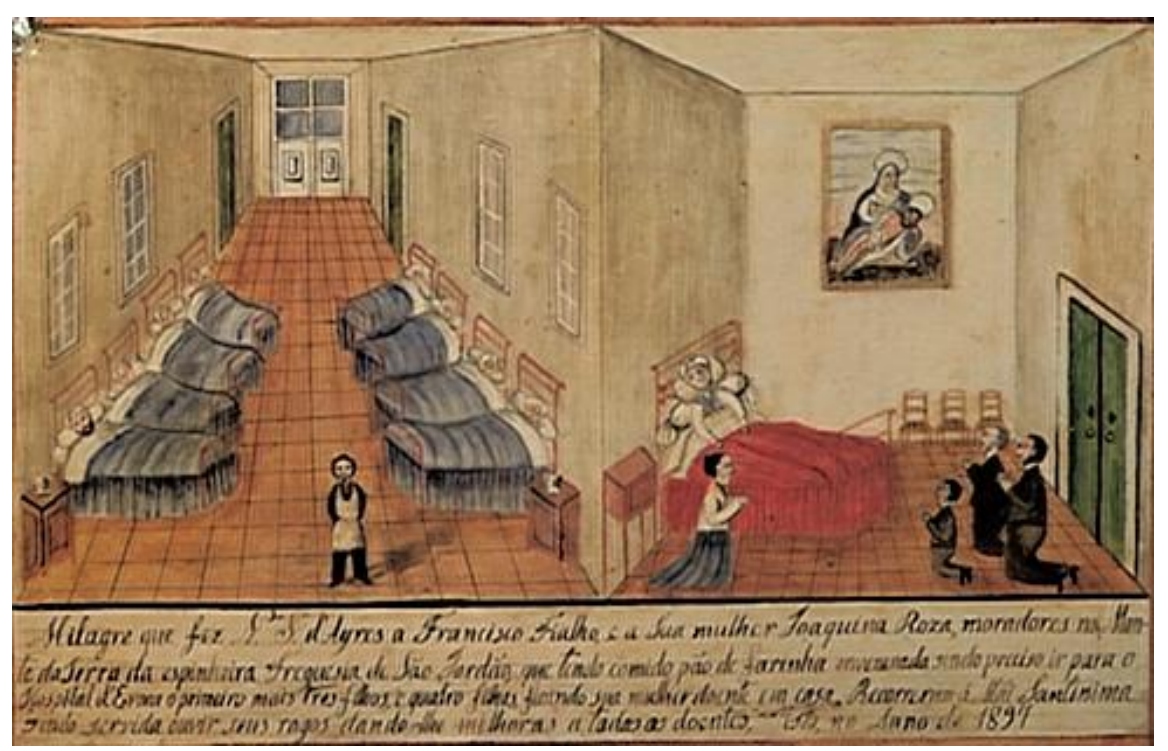

Fonte: Milagre, 1997.

Estes ex-votos, como tantos outros, todos com cenas no interior da casa e até de uma enfermaria, permitem conhecer situações e, em especial, percecionar ambientes domésticos e até um espaço hospitalar. São visíveis peças de mobiliário (camas com e sem dossel, berços, mesas, cadeiras), roupa de cama (colchas, lençóis, almofadas), objetos decorativos (espelhos) e utensílios diversos (pratos, chávenas, etc.). Este tipo de fontes revelam também cenas exteriores. Nesses casos, sobressaem os naufrágios, bem como os problemas e os acidentes envolvendo viajantes e animais. São raros os exvotos que representam simultaneamente o interior e o exterior e, em alguns casos, deteta-se a presença de escravos e até de índios, nos ex-votos relacionados com milagres obtidos no Brasil.

\footnotetext{
10 Transcrição do texto do ex-voto: Milagre que fez Nossa Senhora de Aires a Francisco Fialho e a sua mulher Joaquina Rosa, moradores no monte da Serra do Espinheiro, freguesia de São Jordão, que tendo comido pão de farinha envenenada, sendo preciso ir para o hospital de Évora o primeiro mais três filhos e quatro filhas, ficando sua mulher doente em casa. Recorreram à Mãe Santíssima sendo servida ouvir seus rogos dando-lhe melhoras a todos os doentes, isto no ano de 1897.
} 
Figura 5: Ex-voto relativo a um acidente com animais ${ }^{11}$

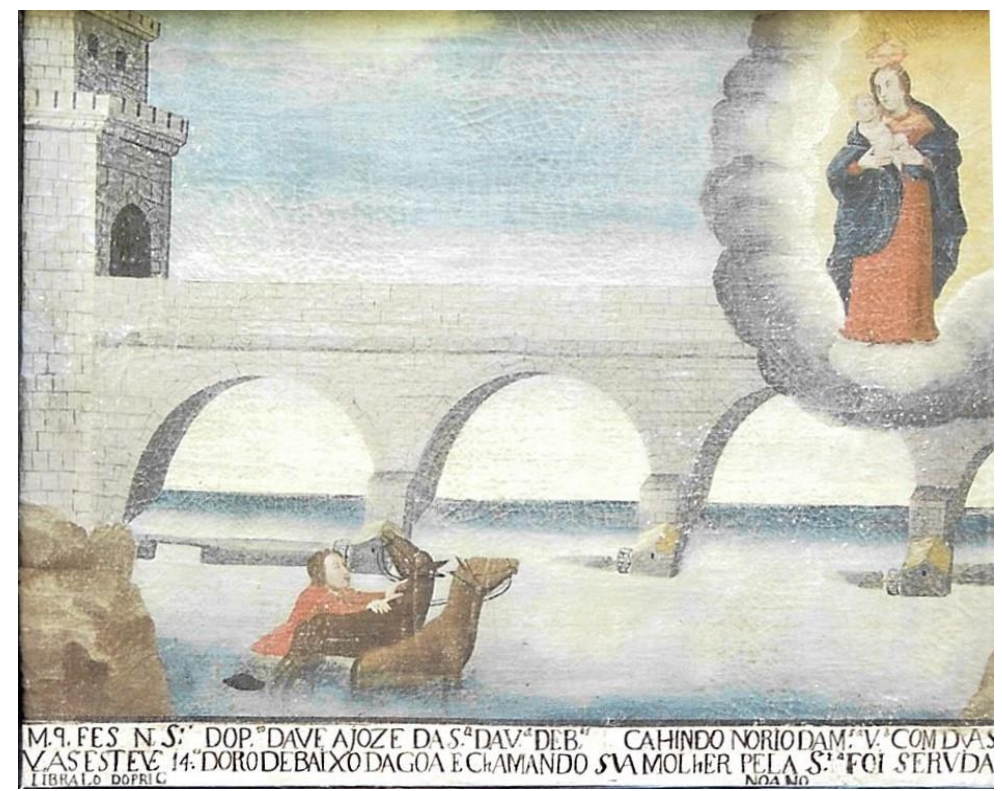

Fonte: ARAÚJO, 2006

Figura 6: Ex-voto relativo a um acidente num rio $^{12}$

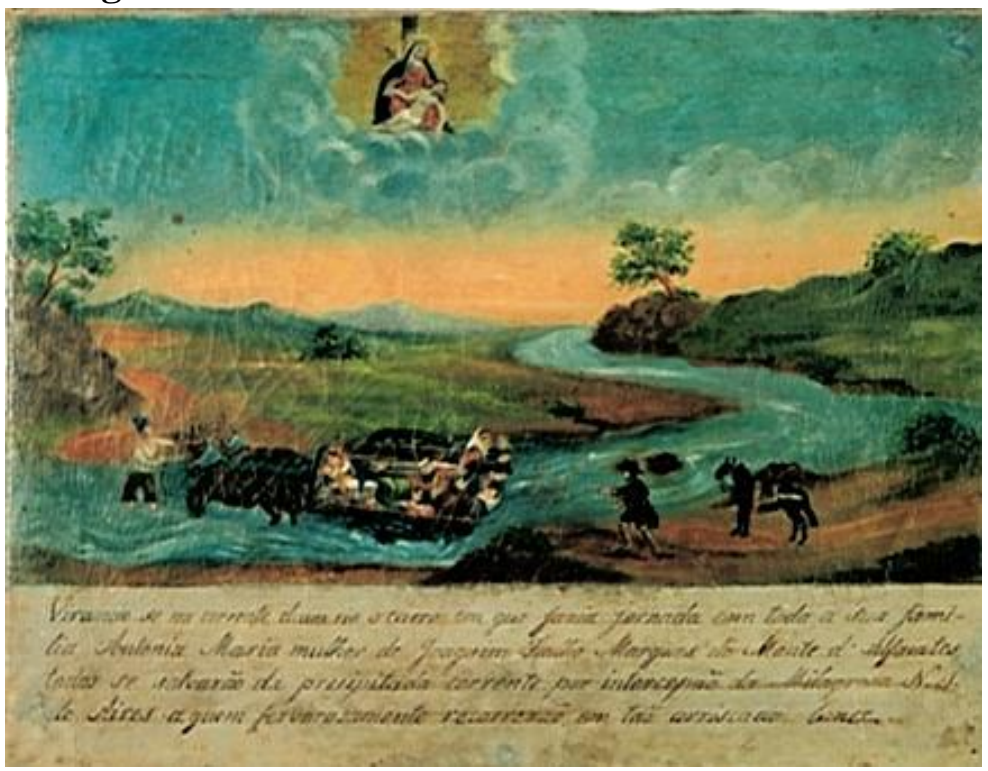

Fonte: Milagre 1997

${ }^{11}$ Transcrição do texto do ex-voto: Milagre que fez Nossa Senhora do Porto de Ave a José da Silva da vila de Bouro caindo no rio da mesma vila com duas mulas esteve 14 minutos debaixo de água e chamando sua mulher pela Senhora foi servida o livrá-lo do perigo.

12 Transcrição do texto do ex-voto: Virando-se na corrente de um rio o carro em que fazia jornada com toda a sua família, Antónia Maria mulher de Joaquim Fialho Marques do Monte de Alfaiates, todos se salvaram da precipitada corrente por intercessão da milagrosa Nossa Senhora de Aires a quem fervorosamente recorreram em tão arriscado lance. 
Figura 7: Ex-voto relativo a um naufrágio ${ }^{13}$

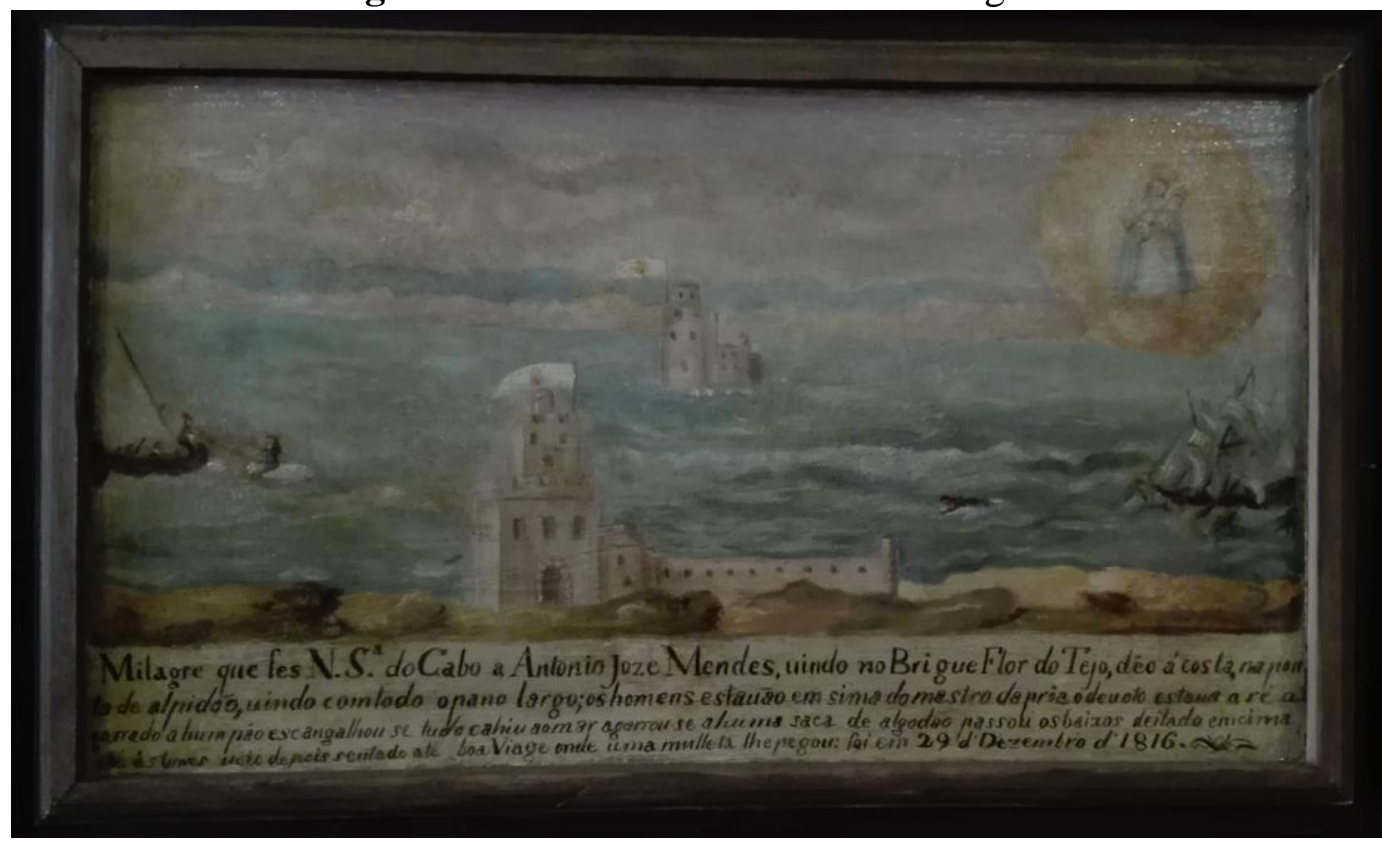

Fonte: Sesimbra, Museu Marítimo de Sesimbra

Figura 8: Ex-voto relativo ao terramoto de $1755^{14}$

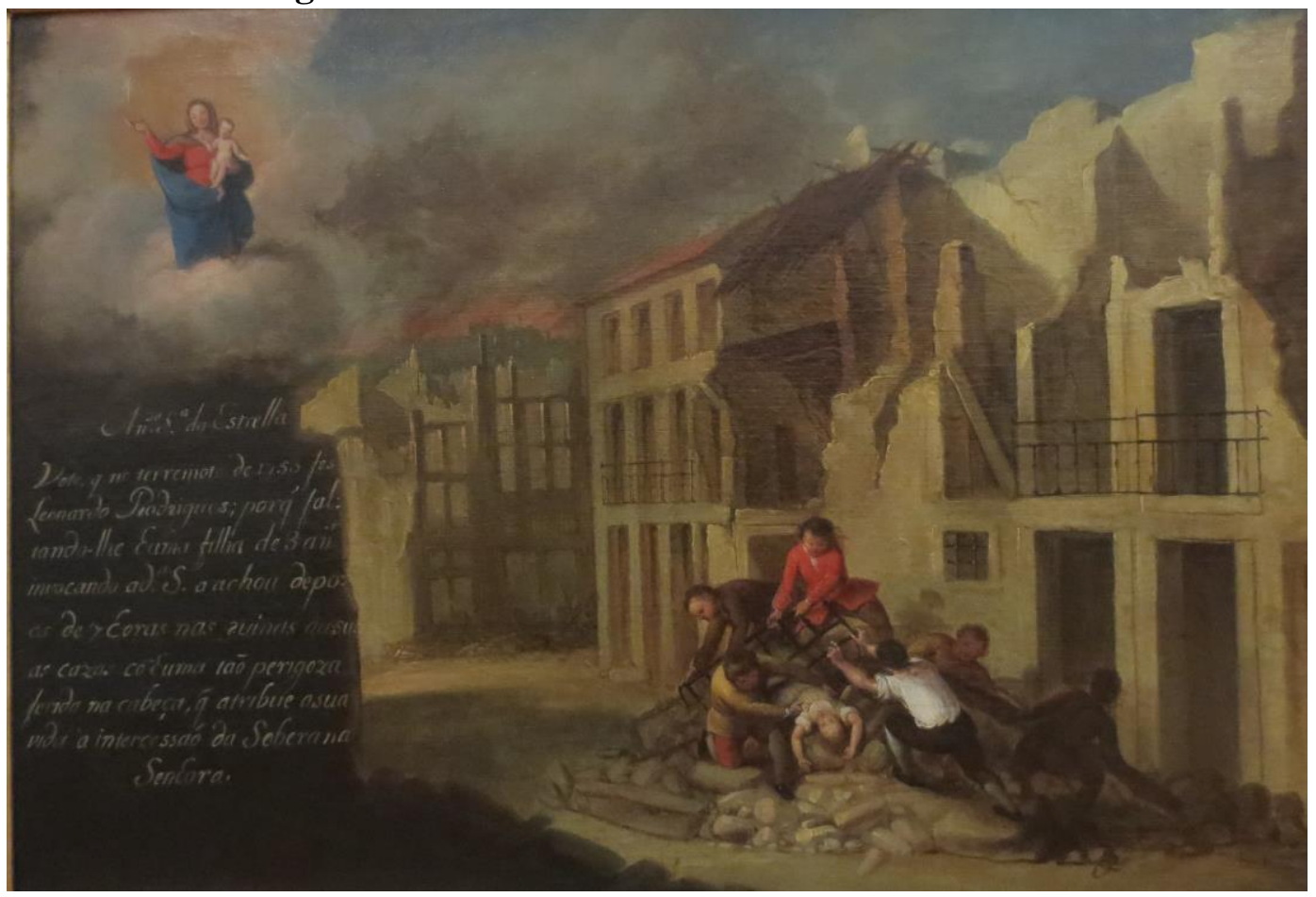

Fonte: Lisboa, Museu de Lisboa

\footnotetext{
${ }^{13}$ Transcrição do texto do ex-voto: Milagre que fez Nossa Senhora do Cabo [Espichel] a António José Mendes, vindo do brigue Flor do Tejo, deu à costa na ponta de Alpidão, vindo com todo o pano largo, os homens estavam em cima do mastro da proa, o devoto estava à ré agarrado a um pau, escangalhou-se tudo, caiu ao mar, agarrou-se a uma saca de algodão, passou os baixios deitado em cima até às torres, veio depois sentado até Boa Viagem, onde uma muleta lhe pegou: foi em 29 de dezembro de 1816.

${ }^{14}$ Transcrição do texto do ex-voto: A Nossa Senhora da Estrela. Voto que no terramoto de 1750 ( sic) fez Leonardo Rodrigues, porque faltando-lhe uma filha de 3 anos, invocando a dita Senhora, a achou depois de 7 horas nas ruínas das suas casas com uma tão perigosa ferida na cabeça que atribuiu a sua vida à intercessão da soberana Senhora.
} 
No exterior, os ex-votos apresentam mares, rios, caminhos, pontes, embarcações, torres, casas e outras construções, animais, por vezes também estábulos, moinhos, noras, meios de transporte (carros, carroças, barcos) e alfaias agrícolas. No caso em apreço, o ex-voto patente no Museu de Lisboa é uma pintura mais erudita do que as restantes aqui reproduzidas e apresenta um erro ao referir o terramoto de 1755 como de 1750. Os efeitos do sismo, designadamente a destruição de casas e o ferimento e morte de pessoas foram devidamente identificados. Já o ex-voto conservado no Museu Marítimo de Sesimbra, revela uma história de naufrágio muito atribulado e em várias fases, como se fossem vários capítulos de uma história.

Comum a todas as pinturas, o facto de representarem indumentárias diversas de crianças e de adultos, de leigos, religiosos e até militares, no caso dos retábulos do século XIX. Em alguns casos, escravos negros e índios também são representados. Os doentes são, por norma retratados envergando camisas brancas. Com um esquema pictórico semelhante, estas peças utilizam também legendas afins. Abunda a expressão "milagre que fez..." e insiste-se num léxico que compreende milagre, acidente e perigo. A datação e a indicação do nome e da atividade de alguns dos miraculados permite conhecer um pouco melhor o universo dos crentes.

Na Época Contemporânea o que permanece e o que muda? Continuam a entregar-se ex-votos com abundância nas ermidas e santuários, mas o suporte dos mesmos teve tendência a conhecer alterações. Se os objetos representativos dos milagres, como partes do corpo humano, continuam a ser em número muito relevante, especialmente os que são de cera ou de madeira, há uma clara tendência de substituição dos quadros gratulatórios por fotografias, com perda de informação relativamente aos miraculados e seus estatutos. Por outro lado, num santuário como o de Nossa Senhora de Fátima, as peças relativas à guerra colonial constituem um conjunto significativo de testemunhos que urge conhecer. 
Figura 9: Ex-votos sob a forma de pernas de madeira. Casa-museu padre Cícero Juazeiro do Norte

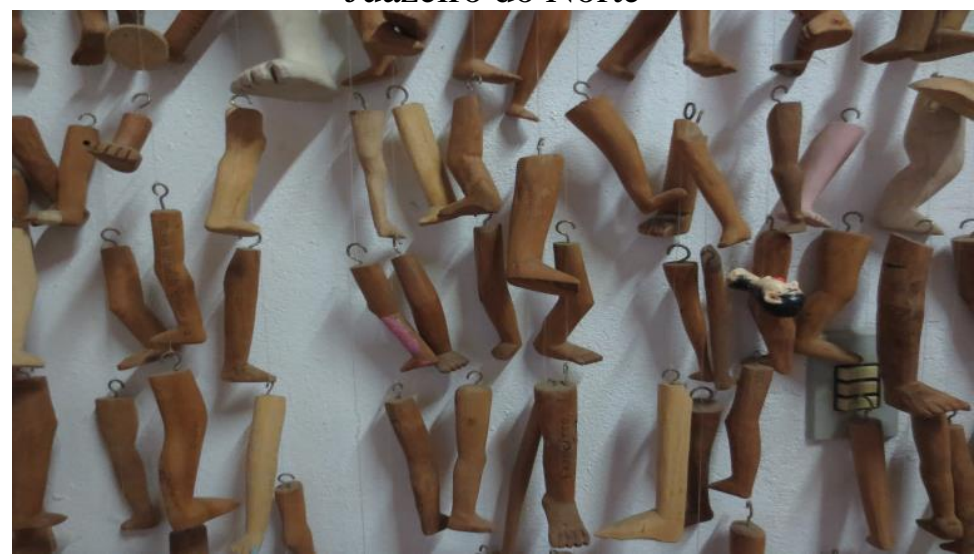

Fonte: Acervo da Autora

Quer nos santuários reconhecidos pela Igreja católica, caso do de Fátima (Portugal), em que abundam os ex-votos, quer nos que não são oficialmente reconhecidos como o do padre Cícero (Juazeiro do Norte-Brasil) ${ }^{15}$, a tipologia dos exvotos é idêntica. Uma novidade chama, contudo, a atenção. Se no passado a conceção do milagre tinha uma relação direta com a obtenção de uma graça que implicava a preservação da vida, na atualidade, a par dessa vertente, encontram-se outras ligadas à obtenção de bens materiais como casas e carros, uma perspetiva materialista totalmente ausente no passado e ao arrepio da definição de milagre anteriormente apresentada.

Figura 10: Ex-voto relativo à obtenção de bens materiais ${ }^{16}$

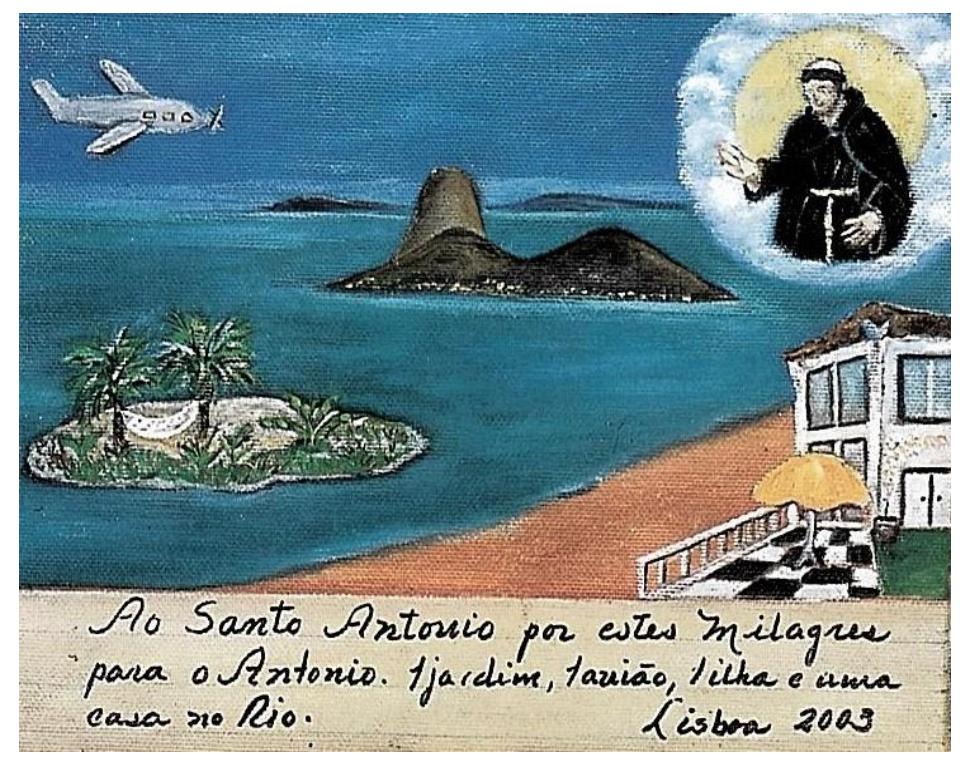

Fonte: REMA, 2003.

\footnotetext{
${ }^{15}$ Sobre este santuário e sobre a figura do padre Cícero, cf. CAVA, 2014.

16 Transcrição do texto do ex-voto: Ao Santo António por estes milagres para o António: 1 jardim, 1 ilha, 1 avião e uma casa no Rio. Lisboa 2003.
} 
Figura 11: Ex-voto relativo à obtenção de uma casa. Casa museu padre Cícero Juazeiro do Norte

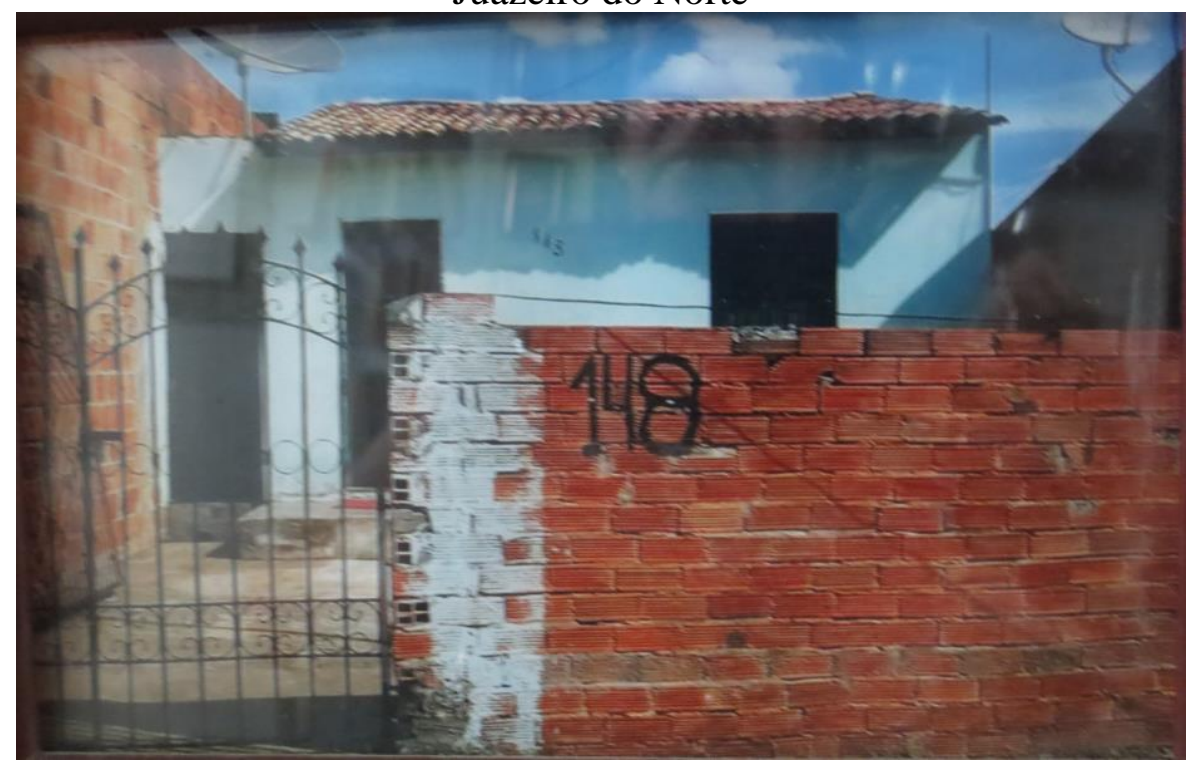

Fonte: Acervo da Autora

Figura 12: Ex-voto relativo à obtenção de um carro. Casa museu padre Cícero Juazeiro do Norte

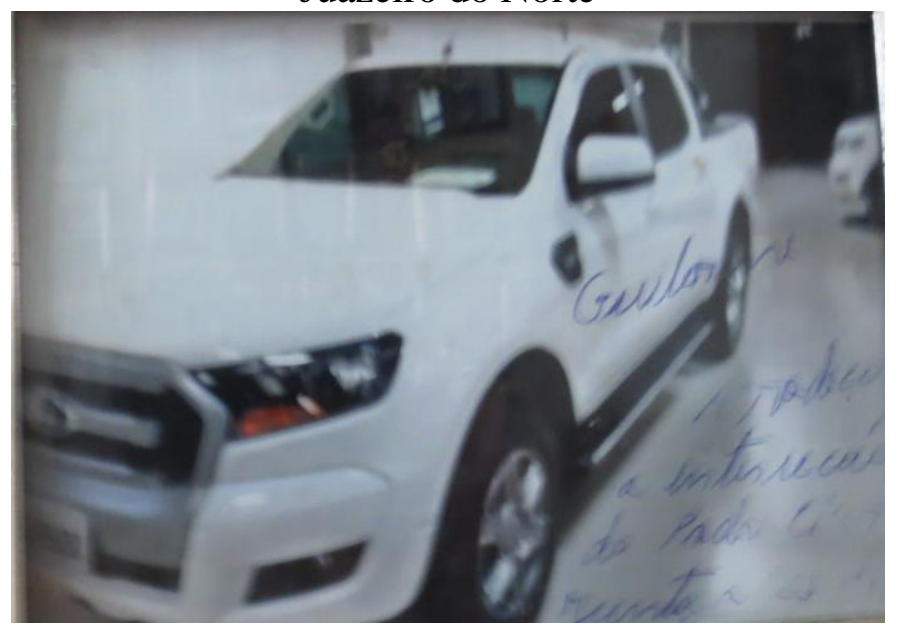

Fonte: Acervo da Autora

Em conclusão, cabe continuar a identificar, catalogar e preservar os ex-votos, disponibilizando ao investigador um corpus documental alargado que permita o conhecimento das formas de religiosidade do passado e do presente, dando a conhecer os espaços de influência dos santuários, os diferentes tipos de peregrinos, os motivos que os levam a peregrinar e os ex-votos que entregam. Por outro lado, se já não se escrevem livros de milagres, existem nos santuários muitas cartas e bilhetes a agradecer as graças alcançadas. Se estes textos não substituem os anteriores, também não deixam de conter informações relevantes que urge conhecer. 
Cabe também perspetivar e equacionar até que ponto se pode identificar exvotos com religiosidade popular. Isto é, se essa identificação não é simplista. Efetivamente, não obstante a esmagadora maioria dos ex-votos pictóricos terem uma feição ingénua e retratarem espaços domésticos modestos, muitos outros apresentam camas com dossel, vestuário sumptuoso envergado pelos retratados e recheios de casa não consentâneos com fracos recursos. As próprias legendas dos quadros votivos, por vezes, aludem do designativo de dom e de dona, e a cargos e funções valorizadas socialmente. Ou seja, estamos perante arte popular mas que não retrata apenas vivências de populares.

Estas e outras questões devem ser objeto de reflexão a partir de um corpus alargado, devidamente estudado na sua geografia e temporalidade, de modo a permitir comparações com situações semelhantes de outros espaços. Por outro lado, cabe refletir na necessidade de rever os conceitos operatórios a utilizar, dando conta da permeabilidade das crenças independentemente do estatuto do crente. Ou seja, em vez de opor religiosidade popular a uma religiosidade mais erudita, valerá a pena desconstruir as divisões e privilegiar que crenças e valores partilham os crentes.

\section{Referências}

\section{Fontes Impressas}

BLUTEAU, Rafael. Vocabulario portuguez e latino. v. 5 e 8, Lisboa: Oficina de Pascoal da Silva, 1716 e 1721.

Estórias de dor, esperança e festa: ex-votos baianos (séculos XVIII-XX). Salvador: Museu de Arte da Bahia, 1999.

Estórias de dor, esperança e festa: o Brasil em ex-votos portugueses (séculos XVIIXIX): guião. [s.1.]: Comissão Nacional para as Comemorações dos Descobrimentos Portugueses, 1998.

Milagre que fez. Coimbra: Museu Antropológico da Universidade de Coimbra, 1997. Imagens de fé: ex-votos da diocese de Portalegre-Castelo Branco, [s.1.]: Câmara Municipal de Castelo Branco, 2015.

REMA, Henrique Pinto. Santo António de Lisboa: ex-votos. Lisboa: Quetzal Editora, 2003. 
ABREU, Jean Luiz Neves de. Difusão, produção e consumo das imagens visuais: o caso dos ex-votos mineiros do século XVIII. Revista Brasileira de História, São Paulo, n. 49, p. 197-214, 2005.

ARAÚJO, Agostinho. A pintura popular votiva no século XVIII: algumas reflexões a partir da colecção de Matosinhos. Revista de História, Porto, v. 2, p. 27-50, 1979.

ARAÚJO, Maria Marta Lobo de. A Confraria de Nossa Senhora do Porto de Ave: um itinerário sobre a religiosidade popular do Baixo Minho. Taíde - Porto de Ave: Confraria de Nossa Senhora do Porto de Ave, 2006.

BEIRANTE, Maria Ângela. O Livro dos milagres de Nossa Senhora das Virtudes: estudo histórico. Azambuja: Câmara Municipal da Azambuja, 2004.

BRAGA, Isabel Drumond. Para a história do medo no Portugal Quinhentista: peste e religiosidade". Revista de Ciências Históricas. Porto, v- 8, p. 83-96, 1993.

BURKARDT, Albert. Les clientes des saints: maladi et quête du miracle à travers les procès de canonization de la première moitié du XVII siècle en France. Roma: École Française de Rome, 2004.

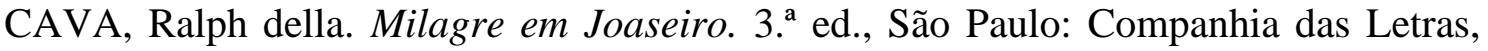
2014.

FERNANDES, Cristina Célia. O livro dos milagres de Nossa Senhora da Oliveira da Real Colegiada de Guimarães (apógrafo de 1351). Porto: Opera Omnia, 2006.

GRILO, Maria Ludovina. A Ermida de Nossa Senhora do Carmo - Azurara e os seus retábulos gratulatórios. A Cidade de Évora, Évora II série, n. 2, p. 141-209, 1997.

GUIMARÃES, João Gonçalves. São Gonçalo de Lagos: hagiografia, culto e memória (séculos XVI-XVIII). Torres Vedras: Câmara Municipal de Torres Vedras, 2004.

HOLMES, Megan. Ex-votos: materiality, memory and cult. In COLE, Michael W., ZORACH, Rebeca. The Idol in the age of art: objetcts devotions and the Early Modern World. Ashgate: 2009.

MENDES, Isabel Maria Ribeiro. O mosteiro de Guadalupe e Portugal (séculos XIV$X V I I I)$ : contribuição para o estudo da religiosidade peninsular. Lisboa: Junta Nacional de Investigação Científica e Tecnológica, 1994.

NOTERMANS, Catrien, JANSEN, Willy. Ex-votos in Lourdes: contested materiality of miraculous healing. Material Religion. [s.1.] v. 7, n. 2, p. 168-193, 2015.

OLES, James. The Virgin doesn't care why yiu fall. Cabinet, Brooklin, n. 54, p. 87-90, 2014.

OLIVEIRA, Ricardo Pessa de. Nossa Senhora das Virtudes: culto mariano e religiosidade popular (Vila Cã, séculos XVI-XIX). [s.1.]: Fábrica da Igreja de Vila Cã, 2019. 
RODRIGUES, Maria da Graça, NAITO, Ricardo. A herança dos milagres - arte, património e cultura: os ex-votos no santuário de Nossa Senhora de Balsamão. [s.d.]. Em linha: http://www.terrasquentes.pt/wp-content/uploads/2018/01/Caderno-4-ATQArtigo-TQ-Gra\%C3\%A7a-e-Naito.pdf. Acesso em 09-01-2020.

SHAW, Jane. Miracles in the Enlightenment England. New Haven, Londres: Yale University Press, 2006.

SIGAL, André-Pierre. L'homme et le miracle dans la France médiévale $\left(X I^{e}-X I I^{e}\right.$ siècles. Paris: Cerf, 1985.

SOALHEIRO, João. Ex-voto. In AZEVEDO, Carlos Moreira de. Dicionário de História Religiosa de Portugal, v. C-J, Lisboa: Círculo de Leitores, 2000.

VAUCHEZ, André. Saints, profetes et visionnaires: le pouvoir surnaturel au Myen Âge. Paris: Albin Michel, 1999.

WARD, Benedicta. Miracles and the Medieval mind: theory, record and event 10001215. [s.1]: Wildwood, 1987.

WIŚLICZ, Tomaz. Ex-votos in the world of objets of polish peasants in the Early Modern times. Acta Poloniae Historica. [s. 1.], n. 102, p. 175-181, 2010. 